\title{
Contributions to the neurobiological study on the structure and relations of the torus longitudinalis in the teleostean brains*)
}

\author{
By \\ Toshihiko Ohta \\ Department of Anatomy, Hiroshima University School of Medicine, Hiroshima \\ and \\ Hiroshima Neurobiological Institute, Kure, Japan \\ (Director: Emer. Prof. N. Suzu ki) \\ with twenty figures
}

\section{Introduction}

The medial part of the tectal gray extends into the ventricle as a paired torus longitudinalis as already noted by many authors, such as Franz ('11), A rïë ns Ka p pers ('21), K u do ('23), A rië n s Ka ppers, Hu ber and Cros by ('36) and recently Y a shiki, Mishima, $\mathrm{H}$ a se g a w a and $\mathrm{I} \mathrm{k} \mathrm{u} \mathrm{ta} \mathrm{('59).} \mathrm{This} \mathrm{torus} \mathrm{is} \mathrm{a} \mathrm{characteristic} \mathrm{brain}$ part which exists only in teleosts and some ganoids as described by $\mathrm{K} \mathrm{u} \mathrm{do} \mathrm{('23,} \mathrm{p.} \mathrm{359).} \mathrm{The} \mathrm{volume} \mathrm{of} \mathrm{this} \mathrm{torus,} \mathrm{is} \mathrm{not} \mathrm{always} \mathrm{parallel} \mathrm{to}$ that of the tectum opticum, as for example in Orthagoriscus, Balister, or Trachinus (see $\mathrm{Kudo}$, '23 or Ari ë n $\mathrm{Kappers,} \mathrm{Huber}$ and Crosby, '36). In its structure and relations, this torus indicates an interesting reference to those of the valvula cerebelli, the torus semicircularis or the commissura posterior. Furthermore; it does never in accord with the development of the tectum opticum or the valvula cerebelli, contrary to the descriptions of the older authors. The connective fiber systems of this torus also indicate various features in its courses. In this research, therefore, some teleosts which havè the developmental disparity of the torus longitudinalis, were examined in order to clarify some questions being included in this brain part.

*) This investigation was supported in part by a grant for the scientific research from the Department of Education of the Japanese Government. 


\section{Materials and Methods}

In this information, the adult brains of teleosts, such as Gadus macrocephalus, Pagrosomus major, Anguilla japonica, Odontobutus obscura, Neoperis sexfasciata and Erynnis edita, were selected. These materials were completely fixed with $20 \%$ neutral formalin and cut in serial sections of transverse, sagittal or horizotal (ca. $15 \mu$ in thickness). These preparations were treated with Pal-carmine, WeigertPal, Sugamo's method and Bielschowsky's silver impregnation. The other series of various teleostean species which have preserved in the Hiroshima Neurobiological Institute, were referenced to the present study.

\section{Description}

\section{Findings in Gadus macrocephalus}

The base of the rostral end of the torus longitudinalis apparently fuses to the dorsomedial part of the torus semicircularis and keenly contacts with the commissura posterior (Fig. 1). The dorsal summit

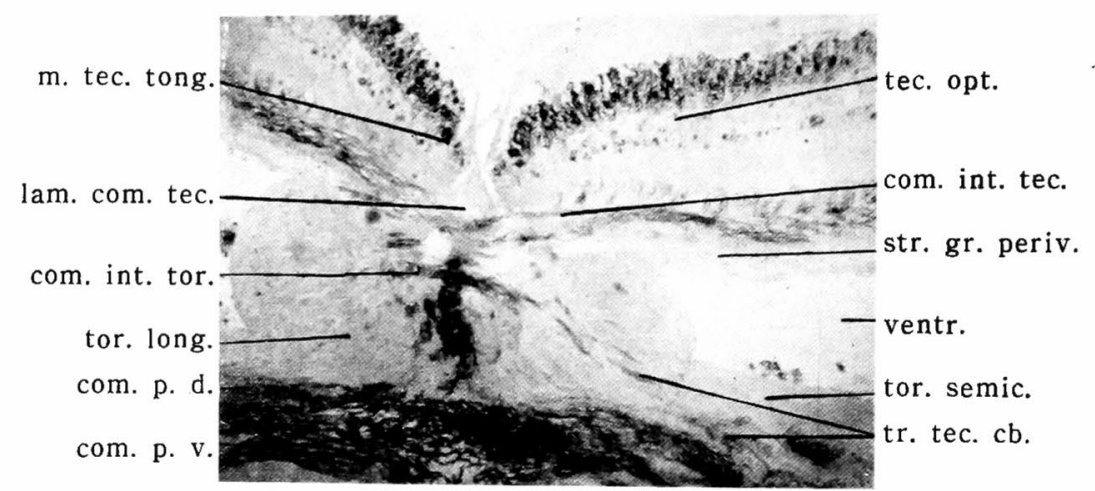

Fig. 1. Transverse section passing through the commissura posterior in Gadus macrocephalus.

of the rostral end of the torus longitudinalis directly continues to the gray of the stratum grieseum periventriculare of the medial tectum tongue. In this section, the valvula cerebelli does not yet come out. The fibers arised from the tractus tecto-cerebellaris ${ }^{11}$ ascend dor-

1) Kudo ('23, p. 363) analyzed the fibers of the tractus tecto-cerebellaris into three groups as followss; the first group runs into the commissura posterior, the second one to the torushalf of the same side and the third to the medial tectum tongue. 
Contributions to the neurobiological study on the structure and relations 47

somedially to enter this torus. Some of them terminate in the same side of this torus and others cross the midline of this torus or intermingle with the fibers of the commissura posterior. But it is uncertain that the fibers from this tract extend dorsomedialward to attain the medial tectum tongue, contrary to the description of $\mathrm{K} \mathrm{udo}$. A few of fibers from the dorsal component of the commissura posterior" take a similar course with those of the tractus tecto-cerebellaris. In the more caudal segment, at the level where the commissura posterior is diminished in its volume, the ventral part of the torus longitudinalis separates from the torus semicircularis. In this section, a few of fibers from the lami commissuralis tecti run into the midline of the torus longitudinalis (Fig. 2). The unmedullated efferent fibers of the torus longitudinalis, tractus toro-tectalis, ascend dorsomedially to enter the tectum opticum as already noted by $\mathrm{Kudo}$ ('23) and $\mathrm{Yashiki}$, $\mathrm{Mishima,} \mathrm{Hasegäwa} \mathrm{and} \mathrm{Ik} \mathrm{uta} \mathrm{('56).} \mathrm{The} \mathrm{intertoral} \mathrm{fibers}$ cross the midline of the torus longitudinalis directly under the commissura intertectalis.

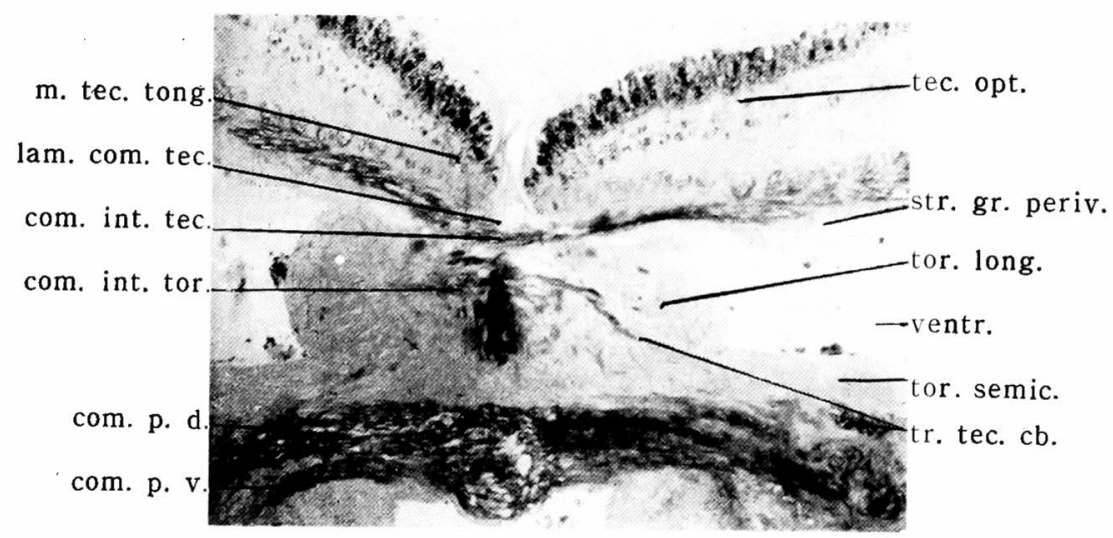

Fig. 2. Transverse section passing through the commissura posterior in Gadus macrocephalus, more caudal to the segment of Fig. 1.

Tracing more caudally, at the level of the caudal end of the ventral part of the commissura posterior, the ventromedial base of

1) In all bony fishes, this commissure consists of two parts, a dorsal and a ventral. There exists a difference of opinion with regard to thc connections of the dorsal part in fishss. Ariëns Kappers (' 07 and '21) believed that it is a commissural connection for the lateral geniculate nuclei in Amia and in Pleuronectidae. Observervers working other fishes (Hoogenboom, ' 29 for Plyodon) have regarded it as commissure for pretectal nuclei, still others have considored that it might carry also tecto-pretectal connections (Ariëns Kappers, Huber and Crosby, '36, p. 918). 
the torus longitudinalis begins to drawn apart from the medial summit of the torus semicircularis (Fig. 3). In this section, the volume of the torus longitudinalis is slightly reduced, while that of the tectum opticum is strikingly well developed in thickness. The valvula cerebelli does not yet present itself. Tracing further caudally. the torus longitudinalis is gradually reduced in its volume, while the valvula cerebelli is moderately well developed with the usual development of the corpus cerebelli.

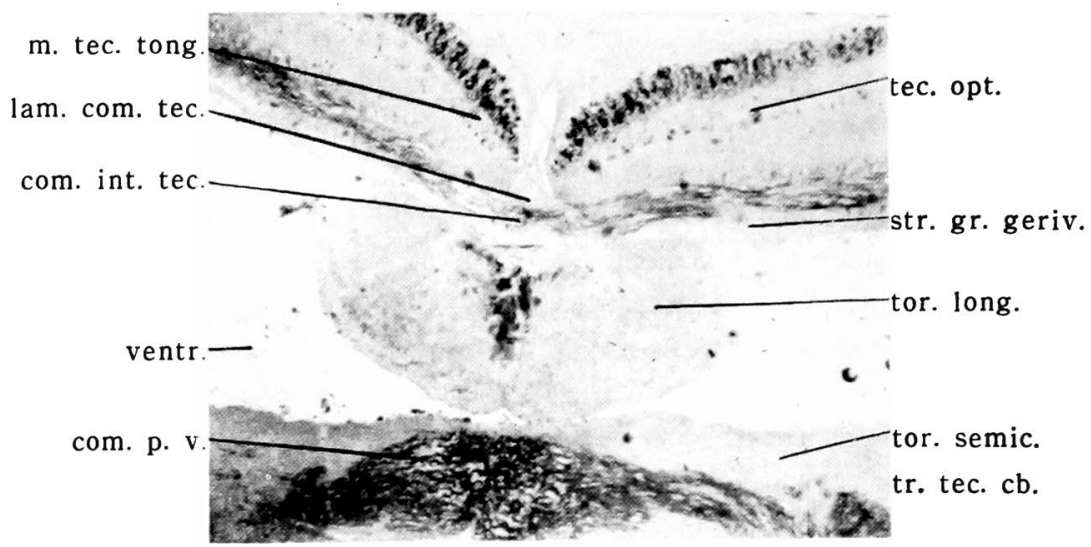

Fig. 3. Transversa section passing through the caudal segment of the ventral part of the commissura posterior in Gadus macrocephalus.

\section{Findings in Pagrosomus major}

At the level of the caudal segment of the commissura posterior, the rostral end of the torus longitudinalis comes out in the ventricle being divided into two halves having a narraw intermediate space between them (Fig. 4). The base of this torus fuses to the dorsal part of the commissura posterior. This torus is not always maximum in its volume at the rostral end where it joins the commissura posterior (see Kudo, '23 and Ariëns Kappers, Huber and Crosby, ' 36, p. 905). In this section, the two halves of the medial tectum tongue are drawn apart and moreover the mndial tectum tongue is rather ill developed than the rest of the tectum opticum. The fibers originated from the tractus tecto-cerebellaris ascend dorsomedially to enter the torus longitudinalis as a compact bundle and then its fibers radiate in the same side of this torus. A few of fibers of this tract join the fiber course of the dorsal part of the commissura 
posterior. The commissura intertectalis is well developed and its commissural fibers cross the dorsomedial vertex of this torus. The unmedullated efferent fibers of the trcctus toro-tectalis ascend dorsalward to enter the medial tectal layer.

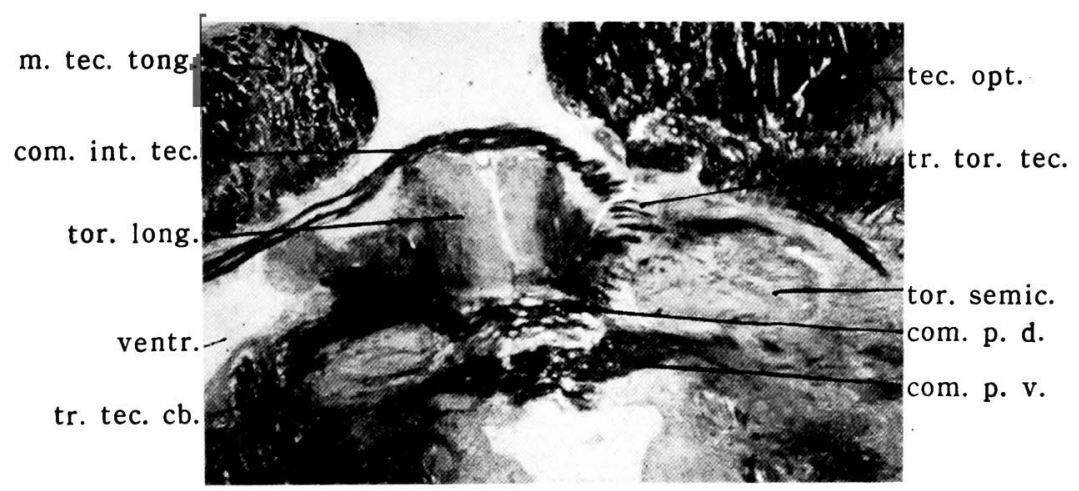

Fig. 4. Transverse section passing through the commissura posterior or the commissura intertectalis in Pagrosomus major.

Tracing more caudally, the torus longitudinalis is gradually reduced in its size and two halves of this torus are quite drawn apart from each other. The afferent medullated fibers of the tractus tecto-cerebellaris are distributed in the dorsomedial area of this torus (Fig. 5). In this section, the rostral end of the valvula cere-

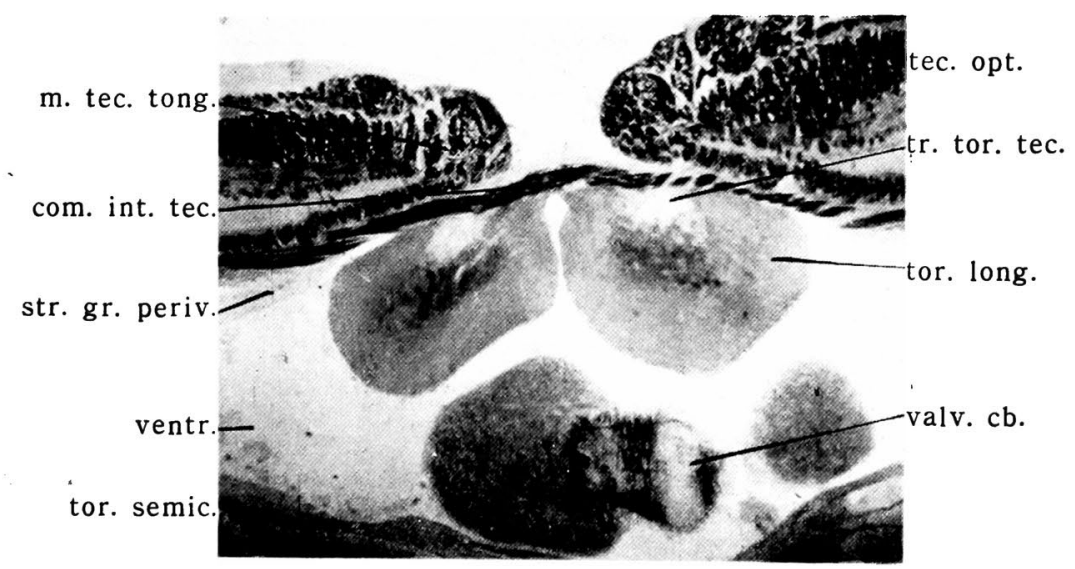

Fig. 5. Transverse section passing through the rostral end of the valvula cerebelli in Pagrosomus major.

belli begins to appear in the ventricle just under the torus longitudinalis. 
Tracing further caudally, at the level of the dorsal motor nucleus of the oculomotorius, the torus longitudinalis becomes smaller with the gradual enlargement of the valvula cerebelli. The fibers of the commissura intertectalis cross the dorsal ridge of this torus (Fig. 6). In this section, the stratum grieseum periventriculare is well developed in its thickness. The efferent fibers of the torus longitudinalis, tractus tecto-cerebellaris, aseend dorsally to enter the tectum without decussation at the midline.

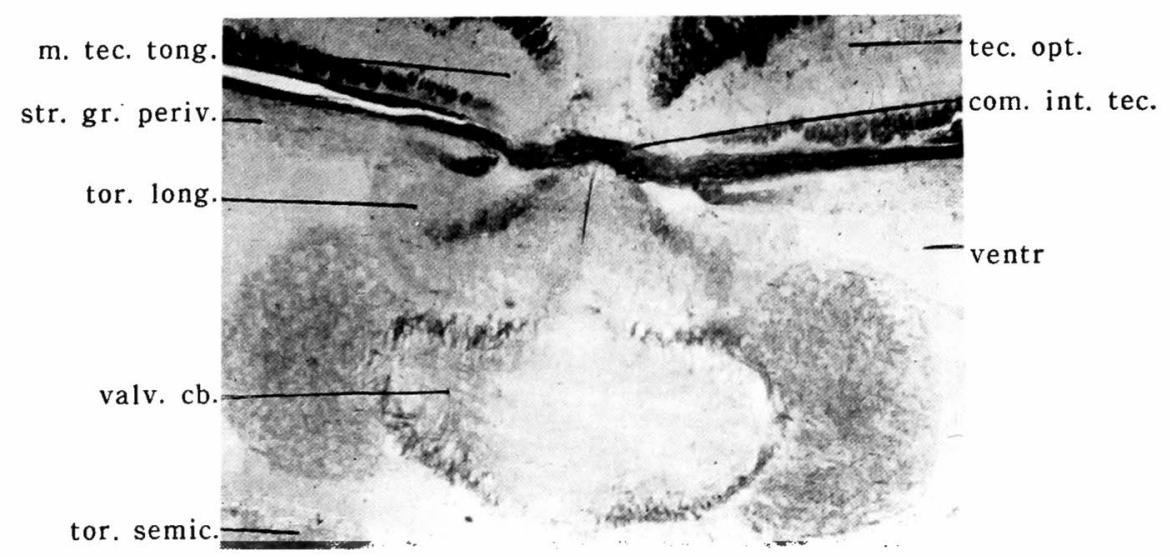

Fig. 6. Transverse section passing through the dorsal motor nucleus of the oculomotorius in Pagrosomus major.

Tracing further caudally, the caudal end of the torus longitudinalis is so diminished as it seems to be an extension of the stratum grieseum periventriculare. The valvula cerebelli becomes smaller by and by, while the corpus cerebelli shows a great enlargement in the ventricle.

\section{Findings in Anguilla japonica}

The torus longitudinalis is diminished in its volume comparing with the well developed tectum opticum. At the level of the commissura posterior, the ventral portion of this torus unites with the dorsomedial ridge of the torus semicircularis. The dorsolateral granular portion of this torus extends to the medial part of the stratum grieseum periventriculare and also the medial part of this torus unites with the stratum album centrale of the medial tectum tongue (Fig. 7). In this section, the fibers of the commissura intertectalis traverse the dorsal vertex of this torus. The feeble fibers of the 


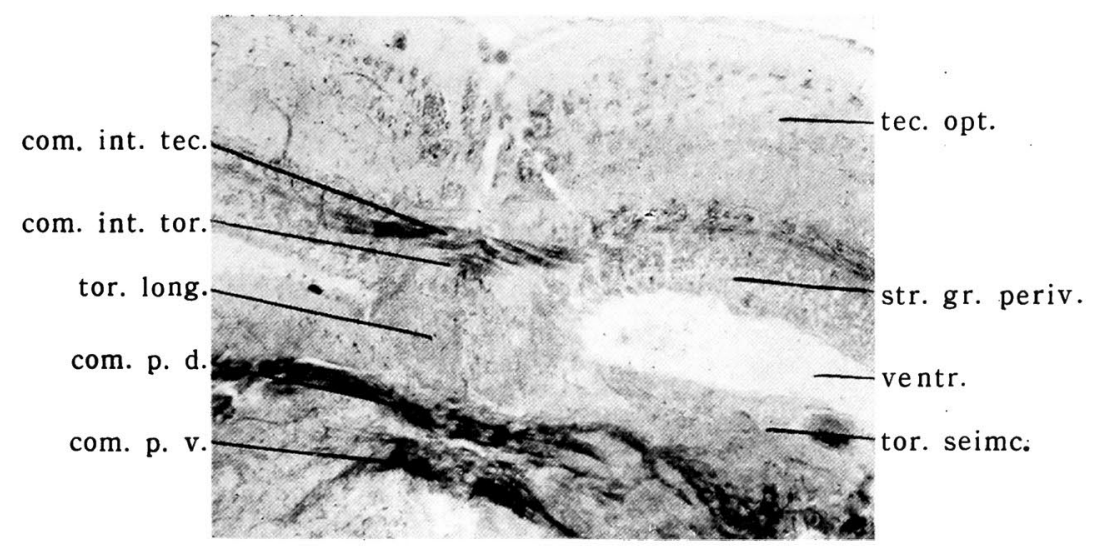

Fig. 7. Transverse section passing through the commissura posterior in Anguilla japonica.

commissura intertoralis is visible just under the commissura entertectalis.

Tracing more caudally, the torus longitudinalis is apparently ill developed and it hangs down as a medial extension of the tectum in the ventricle (Fig. 8). In this section, the valvula cerebelli is considerably well developed lying in the narrow ventricle.

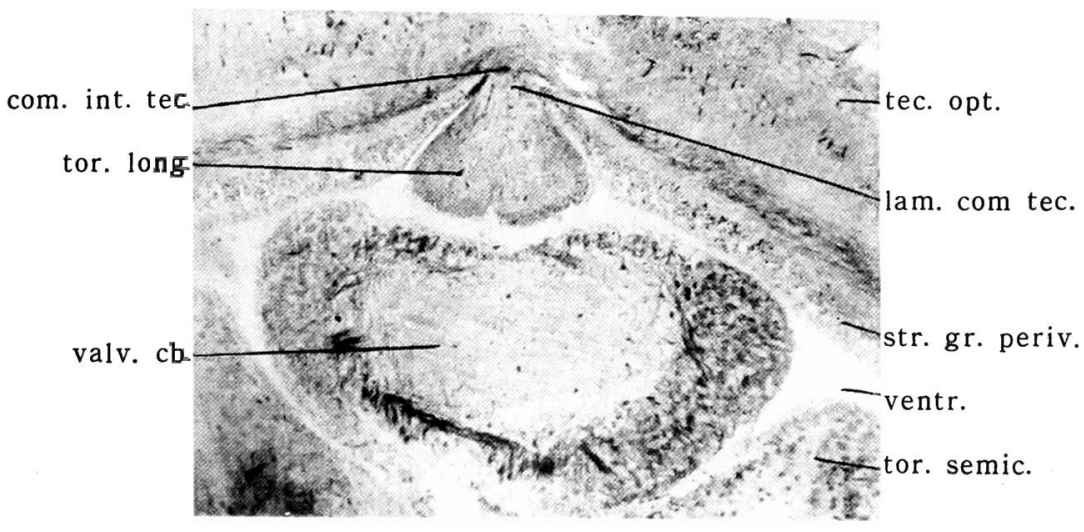

Fig. 8. Transverse section passing through the rostral part of the valvula cerebelli in Anguilla japonica.

Tracing somewhat caudally (Fig. 9), the tectcm opticum is extroardinarily well developed in its volume. The ventricle, however, is filled up with tne strikingly enlarged valvula cerebelli. In this section, the rostral part of the corpus cerebelli begins to appear. 


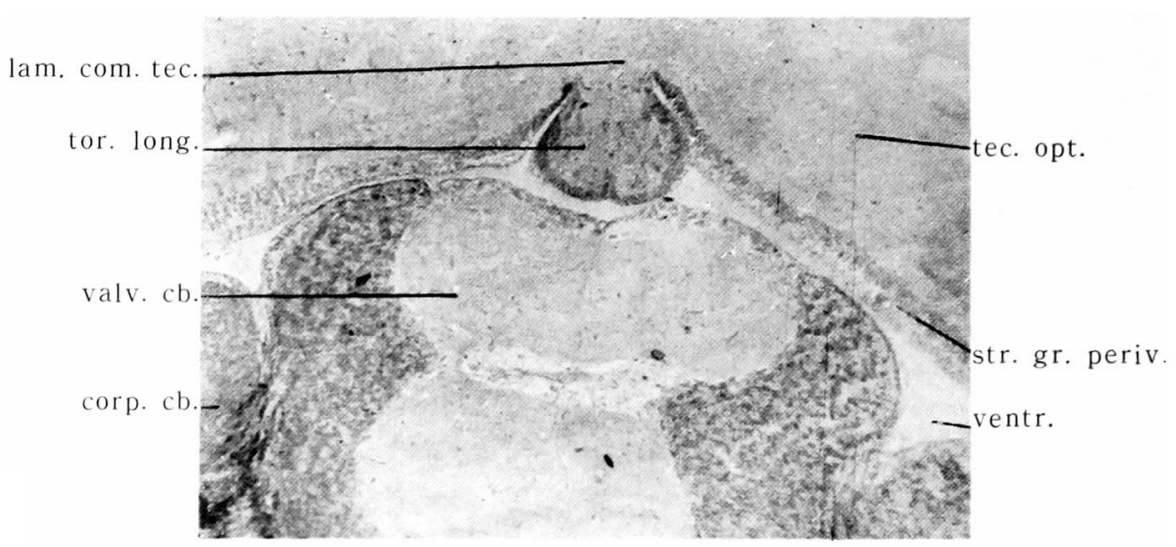

Fig. 9. Transverse section passing through the rostral end of the corpus cerebe!li in Anguilla japonica.

\section{Findings in Odontobutus obscura}

In sagittal series, the rostral half of the torus longitudinalis is rather well develped than the caudal half (Fig. 10). The rostral end of this torus fuses to the dorsal sphere of the torus semicircularis. The compact bundles from the tractus tecto-cerebellaris ascend dorsomedialward to enter the torushalf of the same side. The valvula cerebelli is rather less in development than the cerebellar body, while the tectum is moderately well developed. Tracing more laterally, the unmedullated efferent fibers, "tractus toro-tectal gelatinous fibers of C. L. Herrick". ascend dorsally and penetrate the whole layer of the

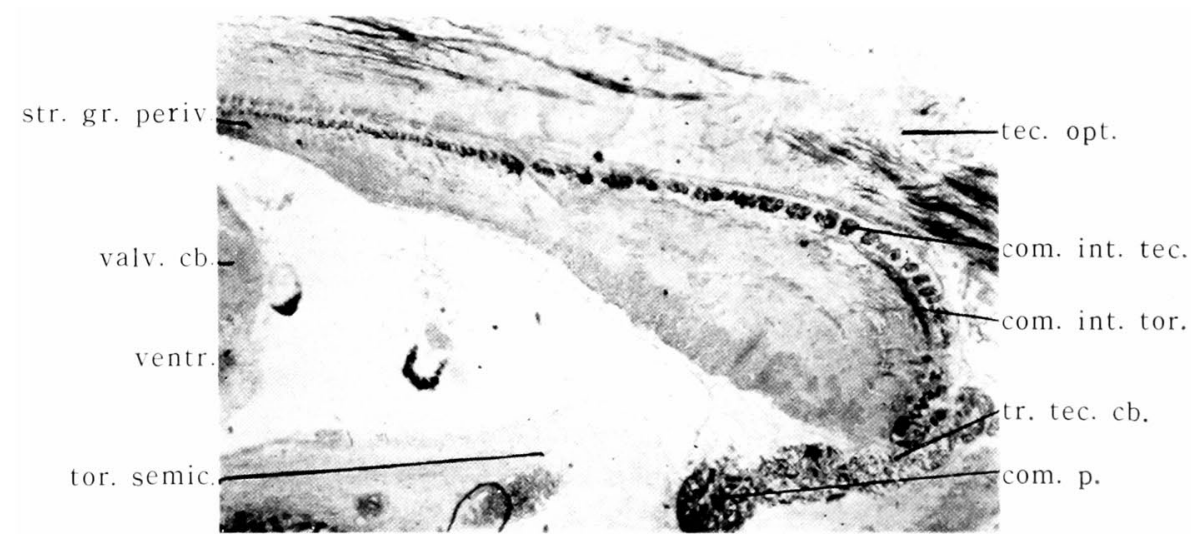

Fig. 10. Sagittal section passing through the somewhat lateral to the midline of the torus longitudinalis in Odontobutus obscura. 
Contributions to the neurobiological study on the structure and relations 53 medial part of the tectum (Fig. 11). In this section, the transections of the medullated fibers of the commissura intertectalis are arranged on the dorsal surface of this torus and the fibers from the tractus toro-tectalis pierce the rostromedial part of this torus but it is uncertain that the fibers of this tract extend to the medial tectum tongue. The granular layer of this torus apparently fuses to the stratum grieseum periventriculare.

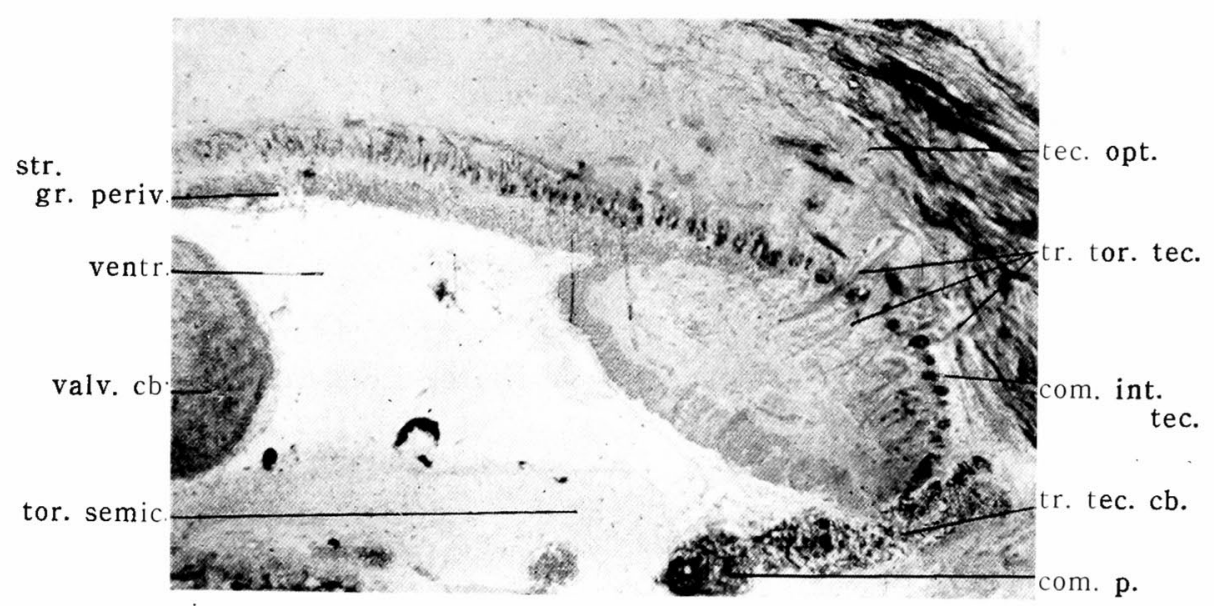

Fig. 11. Sagittal section passing through the midline of the torus locgitudinalis in Odontobutus obscura.

In sagittal series, the fiber systems of the torus longitudinalis, in general, can scarcely be analyzed. The torus longitudinalis is relatively well developed comparing with that of Anguilla japonica. The tectum opticum is, however, ill developed, especially in the medial tectum tongue and in common with the valvula cerebelli.

\section{Findings in Neoperis sexfasciata}

At the level of the commissura posterior, the rostral end of the torus lonitudinalis begins to appear. The ventral surface of this torus fuses to the dorsal surface of the torus semicircularis (Fig. 12). In this sections, the fibers from the tractus tecto-cerellaris stream dorsomedially to enter the lateral half of this torus. Moreover, the fibers from the dorsal part of the commissura posterior enter this torus after they decussated at the median line, while the others terminate in the torushalf of the same side. The fibers of the commissura intertectalis densely traverse the dorsal summit of this 


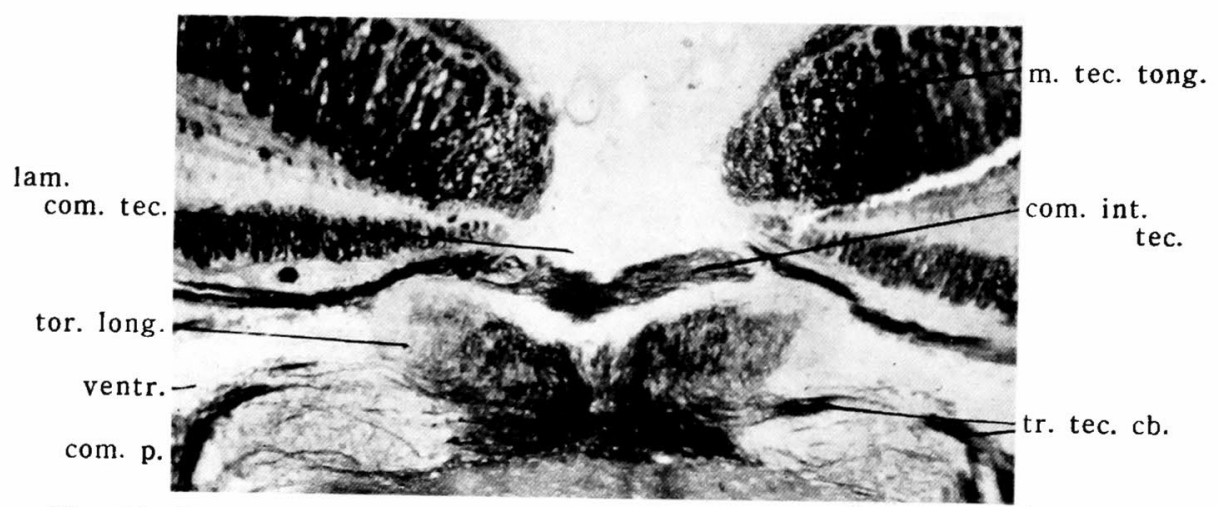

Fig. 12 Transverse section passing through the commissura posterior in Neoperis sexfasciata.

torus.

Tracing more caudally, at the level where the torus logitudinalis does not yet drawn apart from both of the commissura posterior and the dorsal stmmit of the torus semicircularis, the fibers from the tractus tecto-cerebellaris ascend dorsomedially to enter the lateral half of this torus without decussation at the midline (Fig. 13). The thick fibers of the commissura intertectalis cross the dorsal part of this torus. Both sides of the medial tectum tongue are drawn apart at the midline being reduced in its volume, while the other part of the tectum layer is well developed.

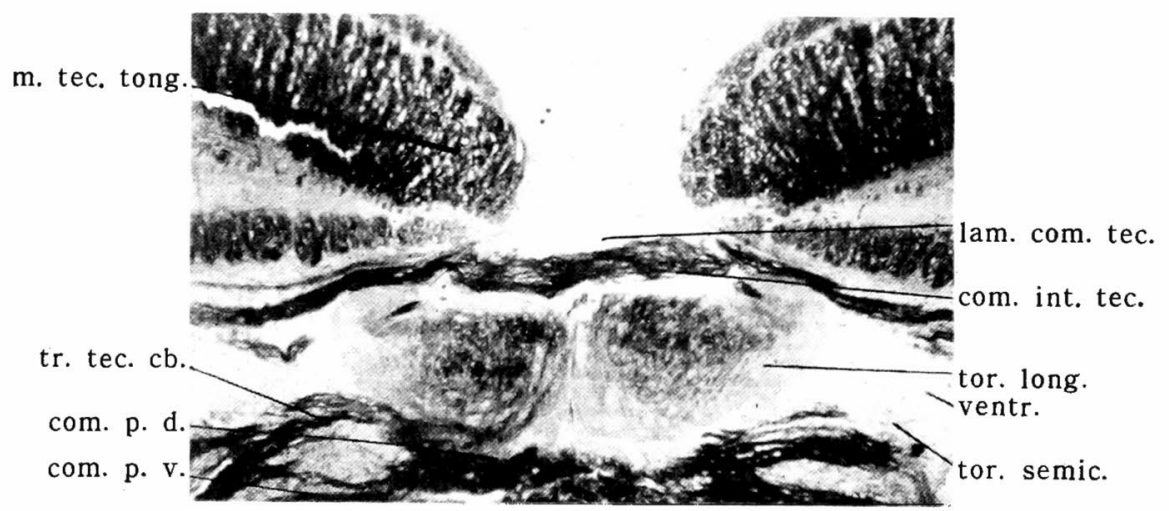

Fig. 13. Transverse section passing through the slightly caudal to the segment of Fig. 12 in Neoperis sexfasciata.

Tracing more caudally, at the level where the dorsal portion of the nucleus oculomotorius motorius begins to appear, the rostral part of the valvula cerebelli is situated just under the caudal segment of 
this torus. In this section, the commissura intertectalis cross the dorsal summit of this torus and feeble fibers of the commissura intertoralis intermingle with the fibers of the commissura intertectalis. The torus longitudinalis is relatively diminished in its volume comparing with that of the valvula cerebelli, while the lateral portion of the tectum opicum is somewhat well developed.

Tracing further caudally, at the level where the ventral part of the nucleus oculomotorius motorius is situated, the torus longitudinalis is quite reduced in its size, while the valvula cerebelli is extroardinarily well developed, so that the ventricle is filled up with it (Fig. 14). The dorsomedial vertex of this torus continues to the lamina commissuralis tecti and the dorsolateral granular part of the torus is also connected with the gray of the stratum grieseum periventriculare. The caudal end of this torus is quite diminished as a paired body, contray to that of Anguilla japonica. In this specimen, the tectum opticum is well developed in its laminal structure.

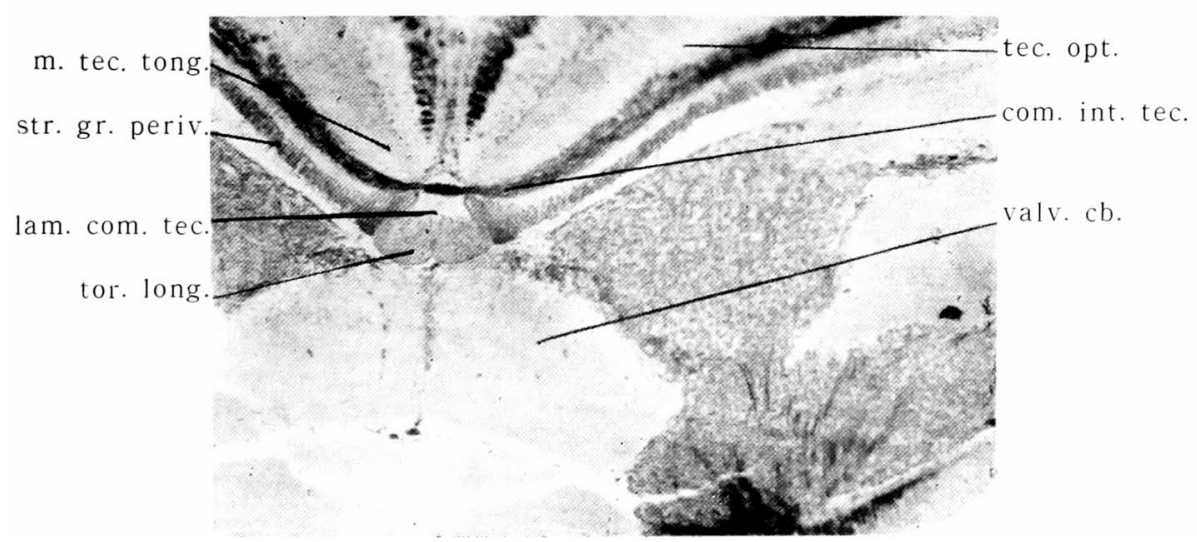

Fig. 14. Transverse section passing through the dorsal motor nucleus of the oculomotorius in Neoperis sexfasciata.

\section{Findings in Erynnis edita}

The torus longitudinalis of this specimen is strikingly well developed comparing with those of the above-mentiond specimens. Besides, the tectum opticnm, the valvula cerebelli and the cerebellar body are generally well developed.

The rostral end of the torus longitudinalis appears at the level of the anterior part of the commissura posterior, being pierced by the well medullated fibers of the commissura intertectalis and the 


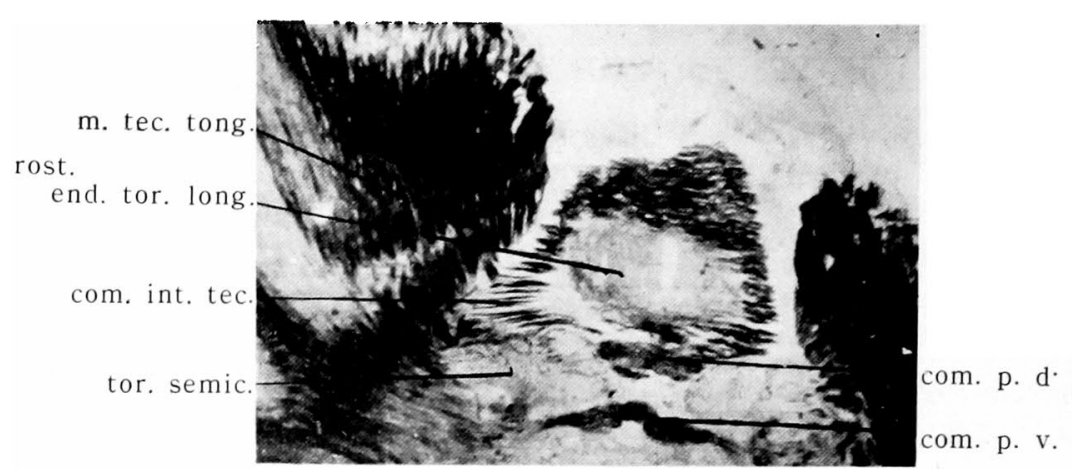

Fig. 15. Transverse section passing through the anterior part of the commissura posterior in Erynnis edita.

fine fibers from the commissura posterior (Fig. 15). The medial tectum tongue is quite well developed.

Tracing more caudally, at the level of the caudal segment of the commissura posterior, this torus shows a gradual enlargement in its size. The fibers of the commissura intertectalis pass the dorsal summit of this torus and the fibers of the commissura intertoralis stream the ventrolateral sphere showing a concaved course (Fig. 16).

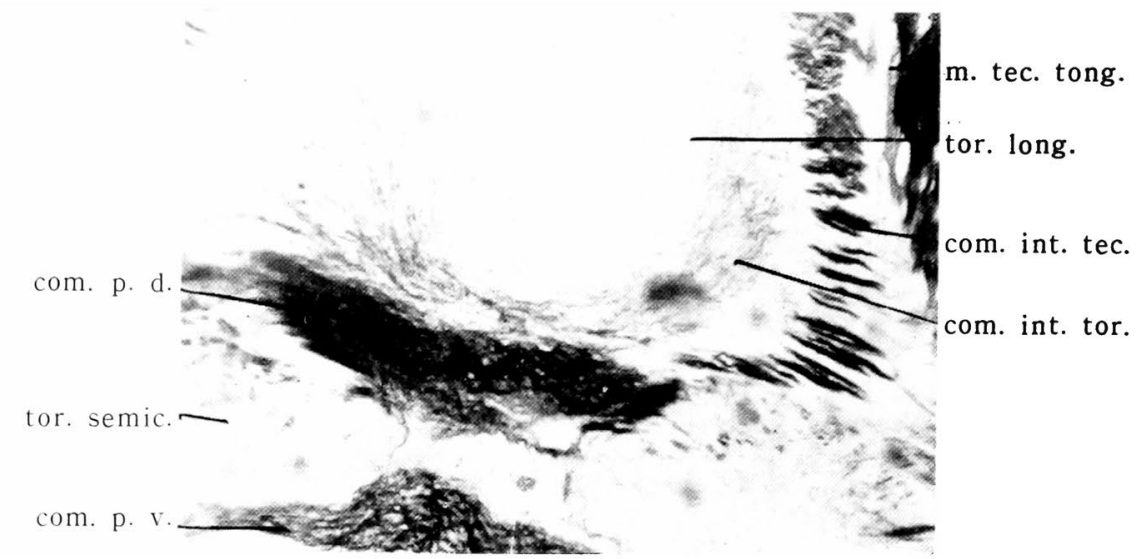

Fig. 16. Transverse section passing through the caudal segment of the commissura posterior in Erynnis edita.

Tracing more caudally (Fig. 17), the fibers from the tractus tectocerebellaris run doresomedially to enter the lateral half of this torus and then ascend dorsalward to radiate in there: Some fibers originated in the tractus tecto-cerebellaris accompany with the commissura posterior. In this section, the fibers of the commissura intertectalis 
pass the dorsal ridge of this torus. It indicates a great enlargement, so that the ventricle is quite filled up with the torushalves. The base of this torus contacts with the dorsal sphere of the torus semicircularis.

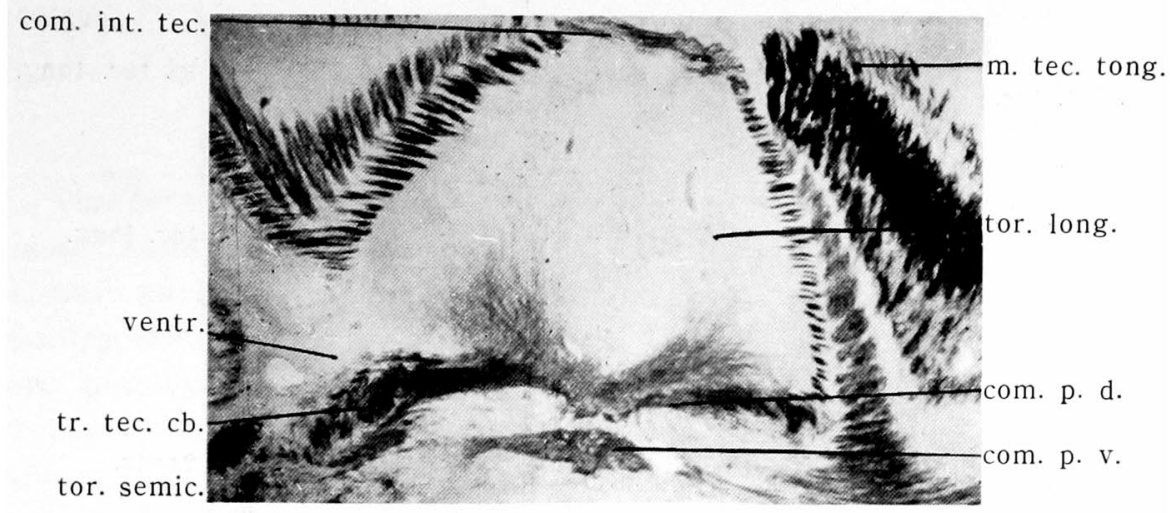

Fig. 17. Transverse section passing through the caudal segment of the commissura posterior pars ventralis in Erynnis edita.

Tracing more caudally, at the level of the caudal segment of the commissura posterior, the most rostral part of the valvula cerebelli begins to appear directly under the ventromedial region of this torus being consisted of two halves (Fig 18). The granular part of the valvula cerebelli directly fuses to the gray of the torus longitudinlis. In this section, the unmedullated fibers of the tractus toro-tectalis ascend dorsolaterally piercing the commissura intertectalis to enter the tetum layer.

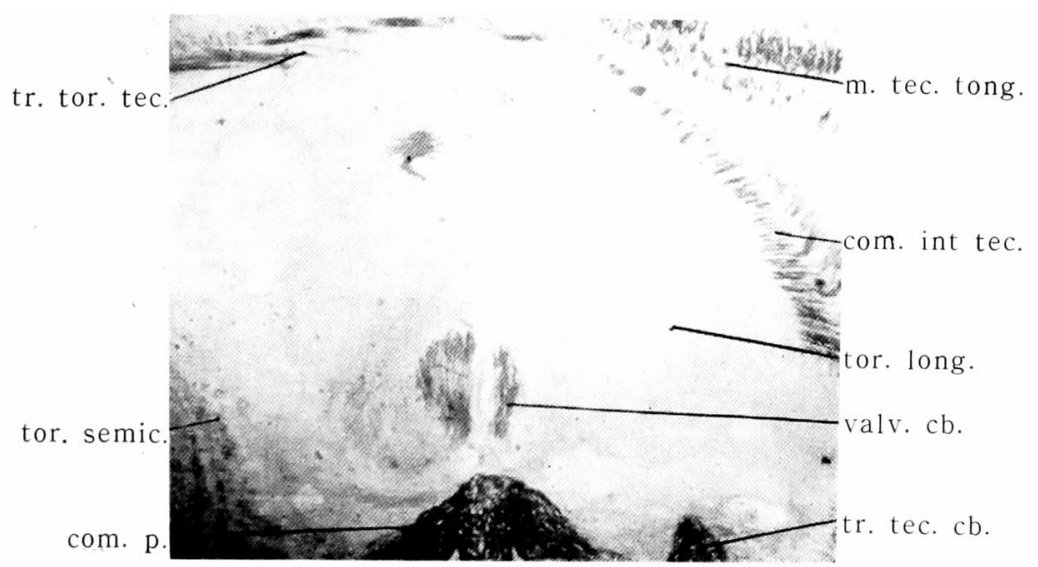

Fig. 18. Transverse section passing through the rostral end of the valvula cerebelli in Erynnis edita. 
Tracing further caudally. the torus longitudinalis becomes smaller with the gradual enlargement of the valvula cerebelli which is situated directly under this torus. The rostral segment of the corpus cerebelli lies ventral to the diminished valvula cerebelli (Fig. 19).

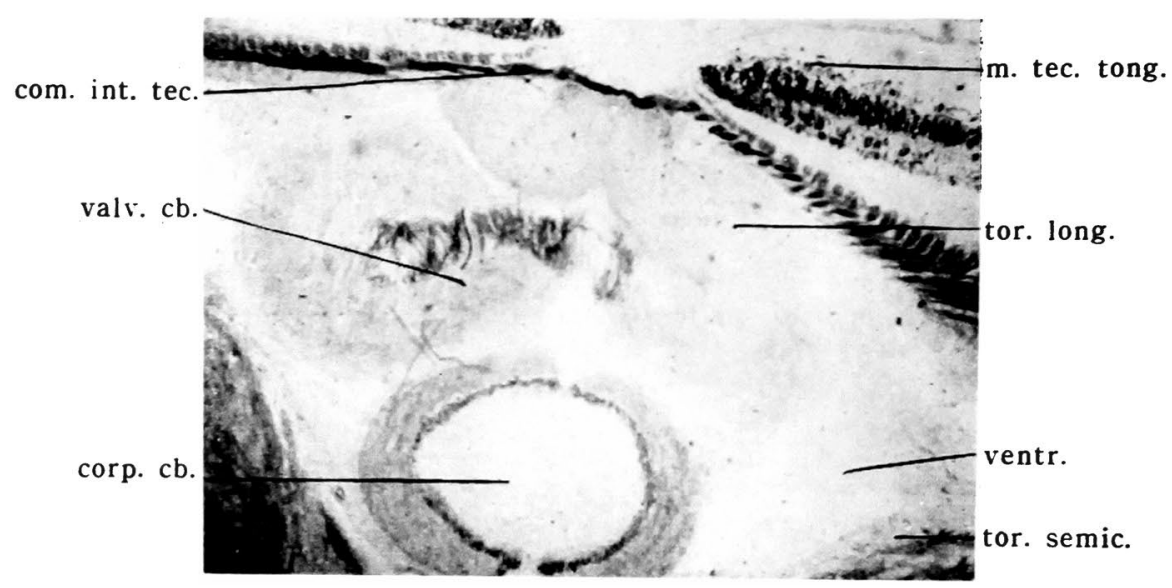

Fig. 19. Transverse section passing through the rostral end of the corpus cerebelli in Erynnis edita.

Tracing further caudally, at the level of the dorsal motor nucleus of the oculomotorius. the torus longitudinalis is quite reduced in its size, while both of the corpus cerebelli and the valvula cerebelli are strikingly well developed. so that the large area of the ventricle is filled up with them (Fig. 20). Even the torushalves are quite diminished at the most caudal segment, they are still corresponded

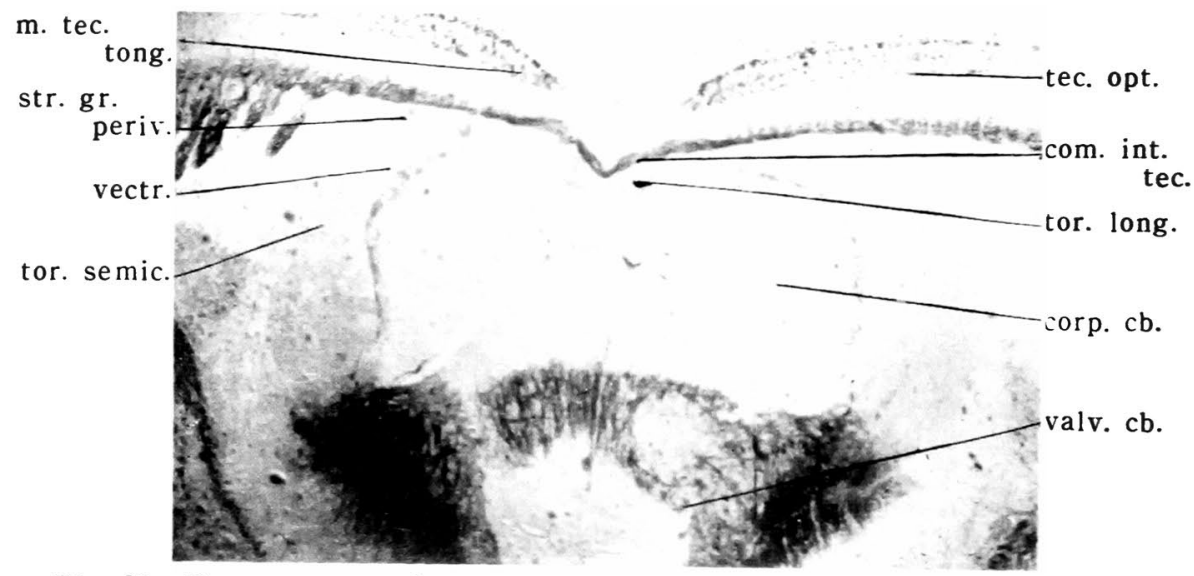

Fig. 20. Transverse section passing through the dorsal motor nucleus of the oculomotorius in Erynnis edita. 
Contributions to the neurobiological study on the structure and relations 59

with those of ill developed specimens as in Anguilla japonica or in Odontobutus obscura. Tne superficial granular layer of the most caudal segment of this torus directly continues to the gray of the stratum grieseum periventriculare as indicated in the above-described species.

\section{Concluding Remarks}

The structure and spatial relations of the torus longitudinalis in teleosts have been observed. For this purpose various species of teleosts, such as Gadus macrocephalus, Pagrosomus major, Anguilla japonica, Odontobutus obscura, Neoperis sexfasciata and Erynnis edita, were employed. These serial preparations were treated with Palcarmine, Weigert-Pal, Sugamo's method and Bielschowsky's silver impregnation.

Although the torus longitudinalis existents only in teleosts and some ganoids as reported by many authors, the development of this torus, especially in its strcture and fiber connections, differs in various species. As for example, it is quite diminished in Anguilla japonica or in Odontobutus obscura, moderately developed in Gadus macrocephalus in Neoperis sexfasciata or in Pagrosomus major and extroardinarily well developed in Erynnis edita. In the fiusion point of the base of this torus and the commissura posterior, as a whole, its volume is maximum and then it is gradually diminished toward both directions of rostral and caudal. This torus is generally consisted of two halves but these caudal torushalves fuse to an azygous body in certain specimen (as for example in Anguilla japonica). On the contray, in such animal as siluroid (A ri u s), where the two halves of the tecum are drawn apart, the torus longitudinalis is divided into two portions (see Ariën $\mathrm{Kappers,} \mathrm{H} \mathrm{u} \mathrm{ber} \mathrm{and} \mathrm{Crosby}$, ' 36 , p. 906 and also Fig. 375, p. 738).

The base of the rostral part of the torus longitudinalis fuses to the dorsal summit of the torus semicircularis, while the dorsal gray of the torus longitudinalis completely continues to the stratum grieseum periventriculare, especially in the caudal segment.

The total volume of the torus longitudinalis is not always parallel to the development of the tectum opticum or especially its molecular layer, contrary to the description of $\mathrm{Franz}$ or $\mathrm{K} \mathrm{u} \mathrm{d} \mathrm{o.} \mathrm{The} \mathrm{develop-}$ ment of the valvula cerebelli and the corpus cerebelli may have preferably a spatial influences upon this torus. 
The efferent fiber system, tractus toro-tectalis, is consisted of special naked neuraxes of so-called "gelatinous tract of C. L. Herrick" as already described by $\mathrm{Yashiki}, \mathrm{M}$ is hi ma, $\mathrm{H}$ a se g a wa and I kuta ('56), and its occurence is not always in accord with the developmental degree of the torus longitudinalis.

Among the afferent fiber systems, the appearance of the tractus teto-cerebellaris is parallel to the development of this torus. Although this tract is divided into three fiber groups by $\mathrm{K} \mathrm{u} \mathrm{d} \mathrm{o,} \mathrm{the} \mathrm{two} \mathrm{groups,}$ namely the fibers run into the torushalf and the second to the commissura posterior, can apparently be estimated but the third group which elongates to the medial tectum tongue is invisible. There exists a difference of opinion with regard to the connections of the dorsal part in the commissura posterior, as commissure for the lateral geniculate nuclei or the pretectal nuclei, but a few of fibers of the commissura posterior, especially those of its dorsal part, penerate the torushalves. The torus longitudinalis may, therefore, play a part of the photostatic function not only the gravistatic function of the midbrain roof, contrary to the suggestion of $\mathrm{K} \mathrm{u} \mathrm{d} \mathrm{o.}$

\section{References}

Ariëns Kappers, C. U., Huber, G. C. Crosby, E.c. 1936 The comparative anatomy of the nervous system of vertebrates, including man. 2 Vols., New York, The Macmillan Company.

Franz, V. 1911 Das Kleinihirn der Knochenfische. Zool. Jahrb., Bd. 32 (c. f. Ariëns $\mathrm{K}$ a p pers, $\mathrm{Huber}$ and $\mathrm{Cr}$ os by, ' 36 and $\mathrm{Kudo}$, '23).

Goldstein, K. 1905 Untersuchungen über das Vorderhirn und Zwischenhirn der einiger Knochenfische, nebst einiger Beitrage über Mittelhirn und Kleihirn derselben. Arch. f. mikr. Anat., Bd. 66, pp, 135-219.

Kashiwamura, T. 1955 Contributions to the comparative anatomy of the tecto-cerebellaris in the brains of some vertebrate. Hiroshima J. Med. Sci., Vol. 3, N0. 3/4, pp. 217-238.

K u d o, K. 1923 Über den Torus longitudinalis der Knochenfische. Acat. Anz., Bd. $52, \mathrm{Nr} .15 / 16$, pp. $359-367$.

Yashiki, K. 1958 On the fine structure of the synapse in a teleostean brain, especially in Mugil cephalus. Hiroshima J. Med. Sci., Vol. 6, No. 4, pp. 365-478.

Yashiki, K., Mishima, K., Hasegawa, T. and Ikuta, Y. 1956 On the connection fibers of the torus longitudinalis in the teleostean brains. Okajimas Fol. anat. jap., Bd. 29, H. 3, pp. 151-156. 


\section{Abbreviations for all figures}

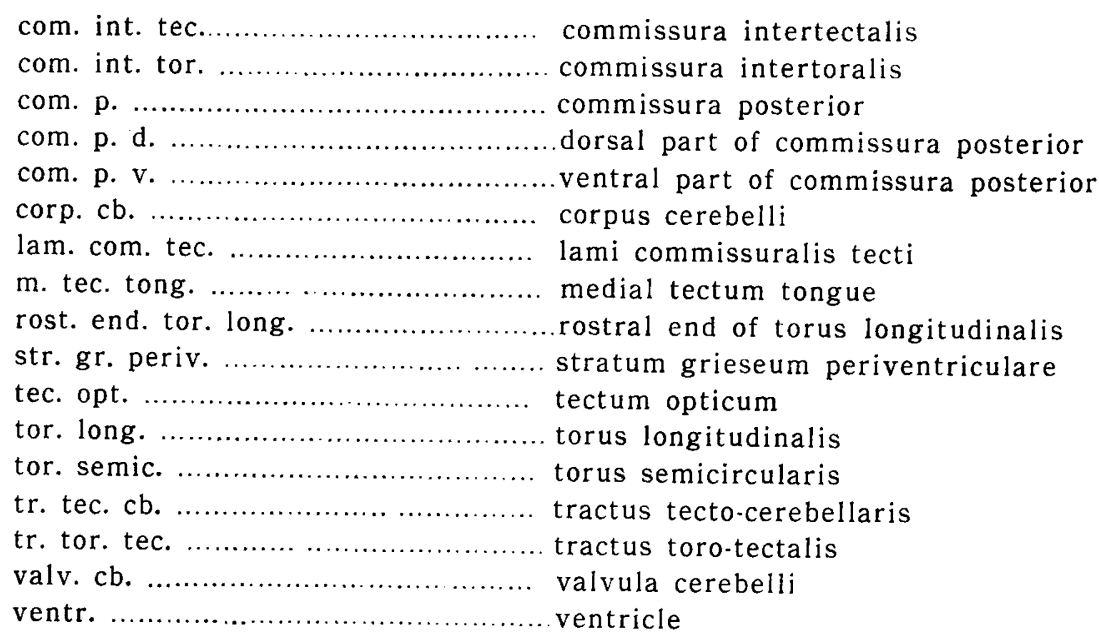

